University of New Mexico

UNM Digital Repository

Mathematics and Statistics Faculty and Staff

Publications

Academic Department Resources

2017

\title{
An Operational View in Computational Construction of Information
}

Florentin Smarandache

University of New Mexico, smarand@unm.edu

Stefan Vladutescu

Constantin Dima

Valeriu Voinea

Follow this and additional works at: https://digitalrepository.unm.edu/math_fsp

Part of the Computational Engineering Commons, Computer Sciences Commons, Digital

Communications and Networking Commons, Mathematics Commons, and the Other Computer

Engineering Commons

\section{Recommended Citation}

Smarandache, Florentin; Stefan Vladutescu; Constantin Dima; and Valeriu Voinea. "An Operational View in Computational Construction of Information." - (2017): 1-8. https://digitalrepository.unm.edu/math_fsp/ 367

This Article is brought to you for free and open access by the Academic Department Resources at UNM Digital Repository. It has been accepted for inclusion in Mathematics and Statistics Faculty and Staff Publications by an authorized administrator of UNM Digital Repository. For more information, please contact amywinter@unm.edu, Isloane@salud.unm.edu, sarahrk@unm.edu. 


\title{
An Operational View in Computational Construction of Information
}

\section{FLORENTIN SMARANDACHE ${ }^{1, a}$, STEFAN VLĂDUȚESCU ${ }^{2, \mathbf{b}^{*}}$, IOAN CONSTANTIN DIMA ${ }^{3, \mathrm{c}}$, DAN VALERIU VOINEA ${ }^{4, \mathrm{~d}}$}

${ }^{1}$ Math. \& Sciences Dept., University of New Mexico, 200 College Road, Gallup, NM 87301, U.S.A. ${ }^{2}$ Communication, Journalism and Education Sciences Department, University of Craiova, $13 \mathrm{~A}$. I.

Cuza Street, 200585, Romania

${ }^{3}$ "Valahia" University of Targoviste, Romania

${ }^{4}$ Communication, Journalism and Education Sciences Department, University of Craiova, 13 A. I. Cuza Street, 200585, Romania

a e-mail smarand@unm.edu, be-mail: stefan.vladutescu@yahoo.com, ce-mail: dima.ioan_constantin@yahoo.com, ${ }^{d}$ e-mail: me@danvoinea.ro

Keywords: technology of information, communication, computation, operation, construction

\begin{abstract}
The paper aims to explain the technology of emergence of information. Our research proves that information as communicational product is the result of processing within some operations, actions, mechanisms and strategies of informational material meanings. Are determined eight computational-communicative operations of building information.

Information occurs in two communication phases, syncretic and the segregation-synthetic. The syncretic phase consists of four operations: referral of significant field, primary delimitation of information, detection-looking information and an anticipative-draft constitution (feedforward). The segregation-synthetic phase also includes four operations: discrimination, identification, interpretation and confrontation (feedback).
\end{abstract}

In the future we will investigate informational actions, mechanisms and strategies.

\section{Introduction}

History is not written by itself, it is the work of a spirit that has seen immediately world upon that reasons or which perceived it mediated by different sources. Information does not appear by itself as information; it involves an effort of observing and implementing in discourse. The spirit is in front of the world which creates an ideal and observes its reality. However, "it constructs the same world, approached in its substance, in the form of an "intellectual" domain [1].

Our domain is information: here human being knows world, he approaches the substance and constructs it informative [2,3]. For construction, we can use synonyms as conception, configuration or creation. Modern man, says R. Barthes [4], "spends all his time reading, he reads before of all images, gestures, behaviors: this can speaks to me about the status of its owner (...), this appetizer, about the lifestyle of my host". World itself, as objective internalized reality "should read" [5]. Reading world is deployed as a construction, as an effort to discern the meanings. "To read, says G. Denhière, means to construct a meaning"; the same idea of reading-construction goes when he asks the researcher to focus him intercession on "constructing the meaning of a text" [6], however it would seem ambiguous [7]. Generally, in communication, the partners irrepressible are engaged not only in communication relation definition, but also in its effective construction [8].

"What are constructing the subjects shows J. Caron [9], it is a meaning." On the other hand, the interlocutory process observation of ensuring a meanings of a statement by a speaker shows that this meaning is not simply just given to be recognized, but as materially constructed during interlocutory exchange, according to a process of sequential compensational ready well formalized by Florentin Smarandache and Ștefan Vlăduțescu (2014) [10] and to which attend the speaker of a words tour and the speaker of the next tour. Communicational meaning of a message is not that literal, but the result of adding literal with additional meanings that occur during communication. The main component of communication, information, it is constituted in the third stage of the communication process, that of processing of the received meanings. Human cognitive subject, in 
state of informational consumer, encounters meanings with a conceptual device and operational capable as a result of different types of "mechanical" processing or strategic to obtain information from raw material [11].

\section{Types of processing}

The processing of semantic material by human cognitive system is performed starting from its physical characteristics or surface (contours, texture, color, movement in space) to the semantic or functional characteristics (category of which takes part, acceptance, function that it has in a given scenario etc.). This type of processing, vectorized from bottom up, from peripheral levels of the cognitive system to the central, is called ascending analysis of the system (bottom-up analysis data-driven processing) $[12,13]$. It is impregnated by the carrier signal characteristics, as well as peripheral cognitive modules properties.

Knowledge of that dispose the subject make possible also other type of processing, reverse vectorized, from its knowledge base to the physical data of the signal. This type of intercession is the descendent analysis (top-down analysis). It is generated based on knowledge of the subject. For example, a word recognition contributes ascending analysis (contour processing letters, size and their shape, clustering them in a unique gestalt based on spatial proximity) but also descendent analysis (inferences generated by the knowledge of a language) $[14,15,16]$.

Descendent analysis explains us why respective word recognition is made easier if it is placed in a meaningful sentence, than meaningless one or why the characteristics of the human face are recognized more quickly if are placed in the context of the human figure than they are presented independently.

The cognitive system disposes of internal process strategies able to execute modular and non-modular processes $[17,18,19,20,21]$. Modular processing is beyond the capacity of intervention of perceiver subject. It would form the autonomous of system perceiver body. Actions, operations, movements and strategies are within the default one, fall within immanence domain, run by itself. Perceiver subject can not oppose to modular processing. This occurs, rather, in absence of attention, as the main form of intentionality, even against attention. Modular processing is preattention or post-attention, it is just simply unqualified with attention criterion: is automatic, mechanical, is produced as mechanism. Furthermore, it is outside of subjective determinants of cognition [22, 23, 24]. Motivation, expectations and presences system, knowledge and cognitive experience have not any influence on this type of processing.

\section{Operations of informational technology}

Informational events are fundamental over determined by the conditions of informational situation in that are entered [25, 26, 27]. Getting information requires an operational technology. In his cognitive approaches, the human subject to grasp the gnosis material, to dominate him, in conditions that his processing capacity is limited and also makes saving (according to the law of minimum effort), is required to proceed some interventions. When it gets to be "aware of them, they become such operations" [28, 29, 30]. "In mental activity, shows J. Piaget elsewhere [26], virtual compensating transformation are actually thought by the subject, he is aware of them and thus become operations". They constitute therefore interventions (transformations) internal conscious and reflect a relationship between the results structures and of its foundations expression. Generally, there are not, problems that confront a matter to be resolved through a single operation. To obtain a result, he must proceed the chaining of operations [31,32]. The same can be said about the informational subject: information is obtained from a series of actions, consisting of operations.

Codification operation is a "transformation". The cognitive operation must therefore be understood as an act through which is transformed a state of knowledge to another [33]. The essential feature of logical thinking is to be operative, i.e. to extend the action internalize it. Operations are not discontinuous and make irrepressible systems. Information technology consists of the assembly operative systems, and not of isolated operations. 
In Professor Mihai Golu's opinion [34] the process is performed operational, in two phases: input organization and information proceed.

According to the first phase are performed three operations:

- exploring (that suppose to pass through semantic field wherefore "searching", coordinates establishing of emitting points of signals and of fixing of some optimal relations of processing;

- detection (means to catch the "presence" of the image and to extract it from the fond elements context);

- codification (registered stimulation after exploring operations and detection is proposed to codification as signal).

The second phase consist of analyze and synthesis of carrier signal, representing a sequence of operations (measuring, correlation, testing etc.) concretized in two "moments" (having each more "steps"):

- discrimination (based on meanings revealing);

- identification (sequence of coincidence tests between actual informational model of the object and storage informational models).

The manner how was transformed the material after operation it is observed after took place already the operation. The indication is constituted what is remaining unregulated, unsorted. The necessity of a new operation, as also itself operation performing is revealed into a clear variable.

The informational object principle shows that in the center of information is variability. Therefore, if after ordering remains a residue variable then is necessary a new operation of a superior force and complexity. Always will remain a "residue", which in communication is composed of "inferences", i.e. from assumptions, implications, questions and instructive.

From meanings that are outside like in a cut shape of sheet it can be deducted the functioning mode of grid $[35,36]$. These meanings carry the processing traces: a square cut in a sheet and taken out of there lets in its place the same square, but empty. The consumer is characterized, therefore, both of what consumes, and also of what he refuses to consume $[37,38]$.

The consumption process takes place through operations and in steps. The receiver must perform a series of operations, the first being the recognition of the language signs or of the type of discourses. Stage two specific rhetoric discourse is that of paradox research, i.e. the recognition and investigation of deviation from the zero degree, experienced deviation as cognitively shock. Recognizing of this paradox is the start of the decoding.

In our opinion, meanings processing occurs in two phases, syncretism and the segregationsynthetic, that supposes more operations for each.

\subsection{The syncretic phase}

It is constituted of 4 performed operations within cognitive system before a nodal delimitation, nucleus of coherent meanings:

i) First operation is represented by perception as presence of field, of zone of meaningful material, what mobilizes the informational grid and brings to allocation of an attention fund and a knowledge quantum of reception. By this is performed outlining of meaningful field.

ii) In presence of meaningful material is executed the orientation in area operation by informational interest centers delimitation.

We associate this to an operation of area direction-investigation, with double function: informational and integrator. Exterior informational outlining is transformed in a map of meaningful "cities", diffuse, relative inaccurate, constituted by informational check points and recognition indications.

iii) It follows entrance into contact with overlap, meaning that the informational grid is applied ascertaining meaningful territory without testing and comparison. It is actually an exploratory of field without internal reproduction [39]. The operation is called detection. Now it is established the absence or presence of potential information of one genre or another. In a heterogeneous field from statistics point of view and semantic-pragmatic, detection will not have an uniform distribution, but appetite, preference: the most frequent will be inspected concentration points of meanings or those which emit signals with "greatest meaning" [40]. Detection that follows 
connection to the informational field represents in essence finding of the object, sets the contact itself with specific object. However the meanings structuring is not produced definitively, their informational character remain global and undifferentiated.

iv) In last operation of the step, anticipative-draft (feedforward), the confused mass of meanings is segmented in sections that could combine into an informational figure registered in a cognitive schema.

\subsection{The segregation-synthetic phase}

In this phase takes place meanings organization: discrimination, identification, interpretation and confrontation (feed-back). The processing needs in this stage a certain order which to allow developing of informational grids components on meanings space. To that effect the meanings are coded, conceptualized and classified [41]. We call the Cover-Thomas Principle the following assertion: "Computation is communication limited and communication is computation limited" [42]. They are not fall on perceptions of a pasive cognitive system. Human subject takes part effectively in the constitution, information forming, it is constructive and creative. Its participation is not limited to a simple ordering or coordination of meanings. Informational spirit operates selections, assemblings and completions of meanings. The organizing of meanings occurs according to principles. Now the informational image loses its global, fragmentary, approximate. It acquires a structure and makes an acceptance.

After meaningful field delimitation and of content outline of the product, after field investigation, it passes to information articulation. From outline it passes to structure.

Detection and preliminary draft confirmed that the meanings can be coagulated into information. After first step we associate virtual information.

In the second stage, the meanings are configured, the information is manifest. If the first stage occurs a radiography of discursive field, representing its topological organization in the second occur filtering and conceptual ordering by highlighting and emphasizing the figure beside the remainder to constitute the fund. It produces synthesis and segregation: takes place infraoperations as measuring, comparing, correlating, integrating, testing and evaluation.

i) First operation is discrimination. It is established on tension created in processing between what tend to be structured as information and what tend to unstructured the informational image, to make of it something known.

Discrimination, as procedural intervention of cognitive material processing, occurs when selected meanings get to be sufficient to reveal the object as figure, ensuring it the individualization and making it unmistakable to others. It is based on an amplification of what was qualified in the previous operations as specific and by an increase, compensation, of the discrepancies and contrasts. Thus the figure becomes quantitatively relevant in relation with the background of meanings. The event requires an infra-operation of quantitative comparison. Now they are differentiated the connected meanings from those that do not bind and thus become parasitic.

Intersections of meanings are separated and is got the first information of assembly from the total of resulting meanings from the acts and informational facts occurred or are in progress in informational situation. In the matter of detection, discrimination separates an operational area. The efficiency of operation depends on the sensitivity of cognitive schemes and information from expectations and presences system, components of the knowledge base of the informational subject. An optimal discrimination suppose that indications of differentiation information grid to have an amplitude and a greater complexity than the investigated field. Otherwise, it gets the task of information structuring to be over consumer "powers". If the volume of meanings is great in relation to processing capacity, take place a deforming selection. It's like a lot of meanings would "fill" in a small bowl: cannot say absolutely exactly where essential not remain somehow outside the bowl. Whatever would be the quantity and quality of meanings, discrimination (good, bad or optimal) occurs [43].

ii) The second segregation-synthetic operation is identification. It has as essence the introduction of discriminated meanings in a measurement system and their reporting to a stored model or to some criteria from operating task constituent of the field. When the resonance of 
structured material occurs with testing criteria in the informational grid, the cognitive system makes the decision "identified": it is information.

Identification appears us as a qualitative operation. Determinations which compound it are made through a sequence of tests of object coincidence with research grid criteria.

Identification can be category type or individual type. The first is achieved by the assimilation trough subordination principle. An informational inedited object is automatically classified in one of the models that we have, in one of the categories that we have in stock: personal information, economic, political etc. The phenomenon is produced by selection after entering the essential features in the category representation, which is to reduce the variations and some of the differences, to mitigate in part the novelty. The inedited object is compressed and are suppressed some of the details, some meanings remain unused. In these cases meanings analysis occurs with large margins of error, because relevance is quantified in relation to a category with a large content, extended. Once performed the category registering, information retrieval process is stopped. This categorization lets us at the surface of things. The inedited contains a novelty that exceeds momentary processing capacity, and cognitive instance limits thus the analysis level to category one. This explains why when we get back to such a material, the ampleness and its novelty, exceeds the gnosis fund that could allocate it, we ascertain with surprise that some information we have lost, we have not noticed, we have not gave them relevance.

Categorical identification involves brutality and imprecision, the normal things any inedited: they represents the defensive reaction to a new that breathtaking. When the novelty, in that it has an experimentalism sub-categories precedent, it is normal limits, identification operation is individual. In fact, it first makes a categorical identification followed by another individual.

Any categorization "favors simplifying" it is a "fundamental cognitive capacity". Initial categorization of the type of individual identification is performed "almost automatically, i.e. involuntary without effort or real consciousness to achieve this process" [44]. Information is simply encoded on the basis of some available indices and their corresponding category in quasiautomatically activated. However, the category indicates not only membership of assigned meanings, but is also call the knowledge contained in these structures, i.e. the scheme.

Category is based on a cognitive scheme: the audible perception "voice" are not videosensations. The category is itself a value judgment, a structure, a cognitive schema in which attributes are organized into easy to emphasize connections. Perception "voice" contains several kinds of knowledge: factual, strategic, tactical and scientific. Possessing this knowledge, the identification process is much easier. Schemata positively influence the speed with which is made perception and structuring of selected meanings. This treatment type of the meanings by schemata is an inherent device in the process of establishing information. The schemata are useful not only in the identification, but also the interpretation of the information sensations [45].

After categorical identification (that uses cognitive schemata) occurs that individual. They are coded (integrated to cognitive own universe each one) particular features, details, fine points. Information is customized. Categorical schema is completed which meanings by which is provided the specific individuality.

After choosing the category "man" are added concrete attributes: "high", "slim", etc. The category and model are formed through learning or come from experience. In relation to certain objects, meanings that we come in current contact perform informational models and individualized sub-models, so that they are privileged selected from the context of the other, certainly and accurate, although indicators as they are revealed are not always aware of being automatic. Thus we identify household things belonging, personal objects, even if they are mixed with others of the same kind, and an outside observer perceives them without finding any difference between them. When cognitive structures become sufficiently developed, identification (categorical or individual) is performed almost immediately, instantly.

If by discrimination is separated informational configuration by the insignificant fund, by identification, after some recognition indicators (novelty, ordering, relevance, utility) is assigned configuration, by relating to a pattern, to cognitive schemata and to informational grid, as 
information.

Identification as information can be made by one or more criteria, or by all criteria which determine the standard information of a certain kind: economic, political, etc. Identification can be done only as a novelty, only ordering, just as relevance or utility, cases which we are dealing with unilateral identification. If it is performed after two: bilateral; three: trilateral, and after four: complete identification or totally. Identification most productive is the connective type, i.e. on more criteria, performed by additive coordinating of informational indications [46]. Conveyed meanings in the informational event (act or fact), are reported by the consumer to a schema and project in them, to find primers, devices and mechanisms which exist in the type of information searched.

iii) Follows transformation of cognition and ordering state of meanings at a higher level: interpretation. If by operations until now it was performed filtering more and more restrictive of meanings until to the essence decanting of information, through interpretation, the configuration gets an acceptance. Interpretation is based on a comparison between the got result and the target at the start of processing and consist of need rationalization what created purposes structures (goals, objectives, interests, aspirations, ideals) through which occurred processing and importance allocation that come to information to achieve some or all pointed purposes [47].

Production and consumption of linguistic communication involves also the operation of interpretation: the acceptance that receiver gives the message depending on the communication context (where there personality, feelings mutual, experience, mood, interactional status of those who communicate etc. Through detection and discrimination we find out the meanings of the message, and through interpretation we attribute our acceptance.

For communication interpretation, I. Dey [48] appreciates reasonable and efficient the following rules:

- messages meanings are dependent of context;

- meanings are the result of some negotiations between communicators;

- meanings and declared intentions to be or to have been followed in communication by communicators has not total validity in interpretation;

- processing character of communication supposes changes and phases.

iv) The last operation is feed-back: to return to the original field of meanings, in order to compare structured information with concreteness of construction material. (This operation may be when it is a set of information base of a feedback strategy) [49]. Now is checked if the acts and facts were receipted appropriate and information detached from the general fund preserves in synthesis its characteristics. Feedback is not reprocessing, but an integrative process by which information is raised above meanings, such as the statue on the pedestal or the title "top" of a work.

\section{Summary}

We prove that information as a cognitive event is a construction. That fact cannot be argued by appealing to evidence. Here we should to appeal to judgment historical arguments, the convergence of epistemological opinions and arguments of authority as also logical and psychocognitive arguments. We showed that information is not an instantaneous event, a light, but a communicative building. In essence, information is a construction of meanings. It is in a process consisting of eight operations. Four operations form the initial phase, called syncretic phase: referral of significant field, primary delimitation of information, detection-looking information and an anticipative-draft constitution (feedforward). The other four form the final phase, also called segregation-synthetic phase: discrimination, identification, interpretation and confrontation (feedback).

\section{References}

[1] F. Smarandache, (T, I, F) - Neutrosophic and I-Neutrosophic Structures. Neutrosophic Sets and Systems (8) (2015) 3-10. 
[2] R. Capurro, What is information science for? A philosophical reflection. Conceptions of Library and Information Science. Historical, empirical and theoretical perspectives, Taylor Graham, London, 1992.

[3] R. Capurro, B. Hjørland, The concept of information. Annual review of information science and technology 37(1) (2003) 343-411.

[4] R. Barthes, L'aventure semiologique, Seuil, Paris, 1985.

[5] L. Quéré, Des miroires équivoques, Aubier-Montaigne, Paris, 1982.

[6] G. Denhière, Le sens, in: R. Giglione (Ed.), L'homme communiquant, Armand Colin, Paris, 1986, pp. 31-46.

[7] G.W. Friedrich, D.M. Boileau, The Communication Discipline. In: A.L. Vangelista, J.A. Daly, G.W. Freidrich (Eds.), Teaching Communication: Theory, Research, and Methods, second ed., Routledge, 2013.

[8] R.T. Craig, Constructing theories in communication research, in P. Cobley, P.J. Schulz (Eds.), Theories and Models of Communication, Walter de Gruyter, Berlin/Boston, 2013, pp. 39-57.

[9] J. Caron, Les regulations du discours, PUF, Paris, 1983.

[10] F. Smarandache, Ș. Vlăduțescu, Towards a Practical Communication Intervention, Revista de cercetare şi intervenţie socială (46) (2014) 243-254.

[11] C. Sdrolia, J.M. Bishop, Rethinking Construction: On Luciano Floridi's 'Against Digital Ontology', Minds and Machines (2013) 1-11.

[12] Weihua Li, Chunyan Yang, Extension Information-Knowledge-Strategy System for Semantic Interoperability. Journal of Computers 3(8) (2008) 32-39.

[13] S. Marcus, Enlarging the Perspective: Energy Security Via Equilibrium, Information, and Computation, Energy Security (2011) 71-78.

[14] C. Zins, Conceptions of information science, Journal of the American Society of Information Science and Technology 58(3) (2007) 335-350.

[15] M. Miclea, Cognitive Psychology, Editura Polirom, Iaşi, 1999.

[16] D. Danciulescu, M. Colhon, Splitting the structured paths in stratified graphs. Application in Natural Language Generation, Analele Stiintifice ale Universitatii Ovidius Constanta-Seria Matematica 22(2) (2014) 57-67.

[17] P. Lindsay, D. Norman, Human Information Processing, Academic Press Inc., New York, 1972.

[18] C.M. Bunaiasu, Teacher's asserting premises and possibilities of efficient managerial styles. Social Sciences and Education Research Review 1(2) 2014 3-10.

[19] J. Henno, Emergence of Information, Communication, and Language, in: P. Vojtas et al. (Eds.), Information Modelling and Knowledge Bases XXIV, IOS Press, Amstedam, 2013, pp. 277299).

[20] Stefan Vladutescu, Ion Cucui, Delia Mioara Popescu et al., Communication in Negative Journalism. In: N. Mastorakis, V. Mladenov, A. Zaharim, et al. (Eds), Conference: 8th International Conference on Management, Marketing and Finances Location: Penang, Malaysia Date: Mar 23-25, 2010 Recent Advances in Management, Marketing, Finances: Proceedings of the $8^{\text {th }}$ WSEAS International Conference (MMF 10) Book Series: Recent Advances in Electrical Engineering pp. 161-165 Published: 2010.

[21] N. Wiener, Cybernetics, third ed., MIT Press, 1965.

[22] N. J. Belkin, Information concepts for Information Science. Journal of Documentation 34(1) (1978) 55-85.

[23] M. Burgin, Theory of Information, World Scientific Publishing, 2010.

[24] D.O. Case, Looking for Information, third ed., Emerald Group Publishing, Bingley, 2012.

[25] D. Chapman, M. Ramage, Introduction: The Difference That Makes a Difference, Triple C 11(1) (2013) 1-5.

[26] J. Piaget, Introduction à l'epistemoligie génètique, vol. 3, PUF, Paris, 1950.

[27] D. Elstner, Information als Prozess, Triple C 8(2) (2010) 310-350. 
[28] X. Negrea, Credibility-an Honest Claim in the Current Romanian Press, Social Sciences and Education Research Review 1(2) (2014) 45-51.

[29] P. Allo, Informational content and information structures: a pluralist approach, in: Proceedings of the Workshop on Logic and Philosophy of Knowledge. Communication and Action. The University of the Basque Country Press, 2007.

[30] W. Hofkirchner, Emergent Information. When a Difference Makes a Difference, Triple C 11(1) (2013).

[31] D.V. Voinea, A demographic portrait of Romanian immigrants In California. Social Sciences and Education Research Review 1(1) (2014) 63-70.

[32] L. Floridi, Information Quality, Philosophy \& Technology 26(1) (2013) 1-6.

[33] J. Grabara, I.C. Dima, Logistics model for industrial waste treatment processes, Social Sciences and Education Research Review 1(2014).

[34] J. Grabara, M. Man, Assessment of logistic outlays in industrial solid waste management, Social Sciences and Education Research Review 1(2) (2014) 11-21.

[35] F. Smarandache, Thesis-Antithesis-Neutrothesis, and Neutrosynthesis. Neutrosophic Sets and Systems (8) (2015) 64-67.

[36] J. A. Swets, Signal detection and recognition by human observers, John Wiley, New York, 1964.

[37] M. Bates, Fundamental forms of information, Journal of American Society for Information Science and Technology 57(8) (2006) 1033-1045.

[38] C. Fuchs, Internet and society: Social theory in information age, London, Routledge, 2013.

[39] J. O'Brien, Football and Spanish Cultural Life; Some contemporary perspectives and observations, Social Sciences and Education Research Review 1(1) (2014) 36-43.

[40] J.A. Bargh, Automatic and conscians processing of social information, in: R.S. Wyer Jr., T.K. Srull (Eds.), Handbook of Social Cognition, vol. 3, Erlbaum, Mahwah, 1984.

[41] I.C. Dima, J. Grabara, S. Vlăduțescu, Comparative Study on Online Education in Romania and Poland in Terms of Current Globalization. Polish Journal of Management Studies 10(1) (2014) 7-18.

[42] T.M. Cover, J.A. Thomas, Elements of information theory, John Wiley \& Sons, 2012.

[43] S. Kot, B. Ślusarczyk, Aspects of Logistics in Biomass Supply for Energy Production. Applied Mechanics and Materials 309 (2013) 206-212.

[44] E. Unguru, A. Sandu, A Socio-Legal Approach of Probation in Light of the New Penal Code. Restorative Justice versus Retributive Justice, European Journal of Law and Public Administration (1) (2014) 37-68.

[45] N.R. Stan, The relation between human dignity and human rights in the Orthodox perspective, Institut oecuménique, 2008.

[46] X. Negrea, Objectivity between illusions and professional standards in today's journalism, Social Sciences and Education Research Review 1(1) 2014 29-35.

[47] A.E. Ranta, The Communication of Local Public Authorities with Mass-Media. Effects and Best Practices, Transylvanian Review of Administrative Sciences 7(34) 2011 201-216.

[48] I. Dey, Qualitative data Analyses, Routledge, London, 1993.

[49] M. Norton, Introductory concepts of Information Science, Information Today, 2000. 